\title{
Dynamic epigenome changes in response to light in Brachypodium distachyon
}

\author{
yunyun $\mathrm{An}^{1}$, Wei Shen ${ }^{2}$, Jianjian $\mathrm{Li}^{2}$, Silin Zhong ${ }^{2}$, and Pinghua $\mathrm{Li}^{1}$ \\ ${ }^{1}$ Shandong Agricultural University \\ ${ }^{2}$ The Chinese University of Hong Kong
}

October 22, 2020

\begin{abstract}
Light plays an important role in many plant biological processes such as photosynthesis and photomorphogenesis. In this study, we applied RNA-seq, ATAC-seq and ChIP-seq to study transcriptional regulation at multiple levels in Brachypodium distachyon (B. distachyon) under controlled light and extended darkness conditions. We have identified 8,400 differentially expressed genes (DEGs), and they are enriched in photosynthesis Gene Ontology terms. ATAC-seq signal decreased after extended darkness, indicating that light has a genome-wide impact on chromatin accessibility. We also found that differential H3K4me3 and H3K9ac modifications are enriched in gene loci associated with photosynthesis and other light-dependent reactions. Finally, ChIP-seq revealed that a HY5-Like transcription factor could directly bind to the promoter open chromatin regions of these light reaction genes. Taken together, our results indicated the dynamic transcriptional reprograming associated with light-dark changes in Brachypodium could be resulted from the combinatorial action of multiple epigenetic features.
\end{abstract}

\section{Hosted file}

PCE-v3.pdf available at https://authorea.com/users/369475/articles/488311-dynamic-epigenomechanges-in-response-to-light-in-brachypodium-distachyon 


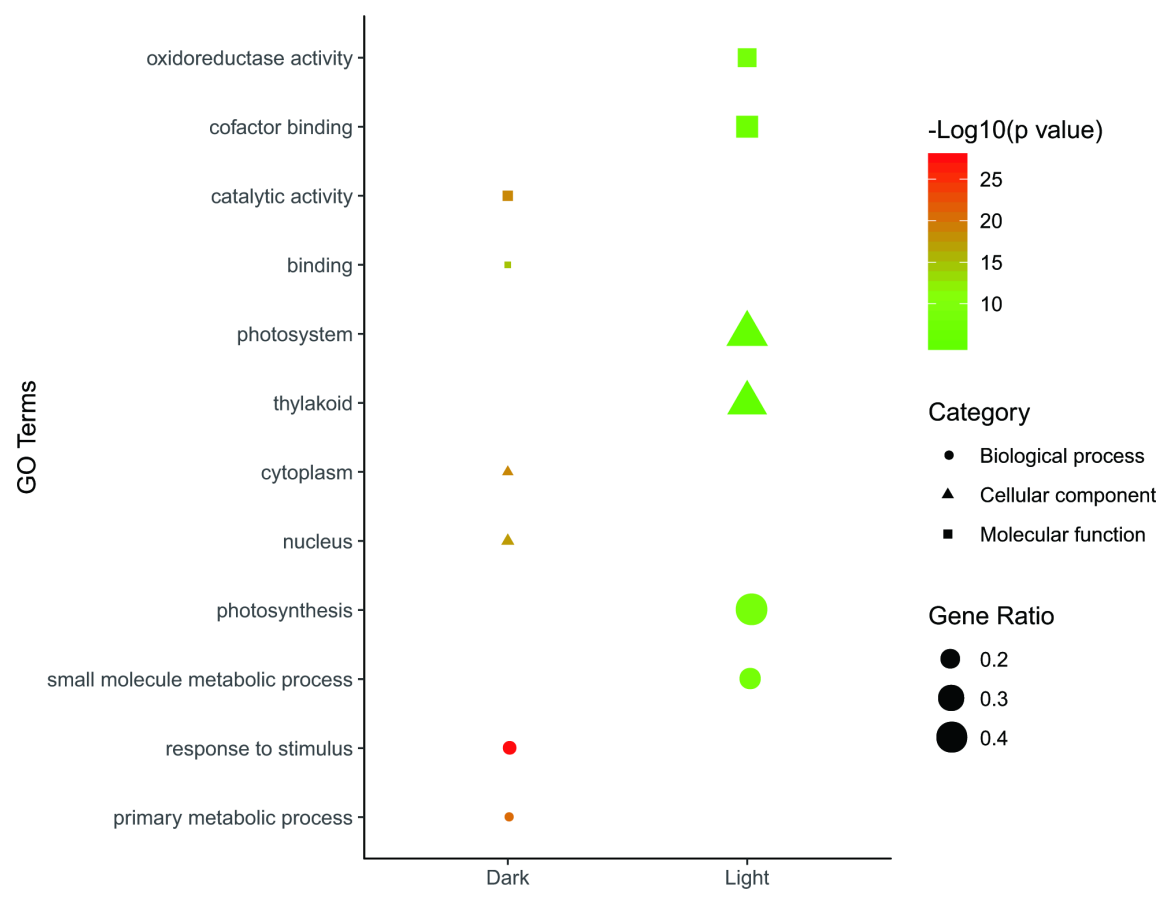


(a)
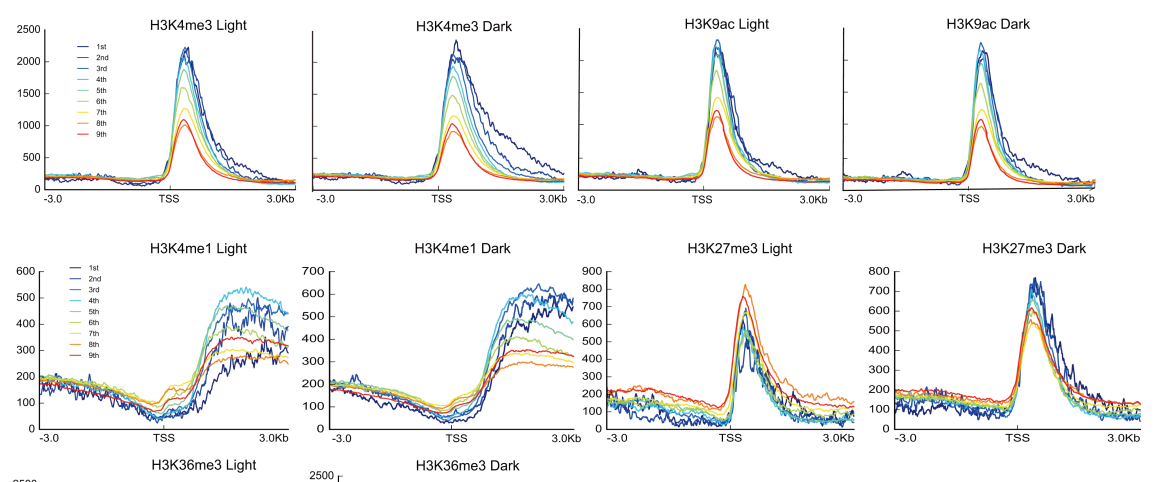

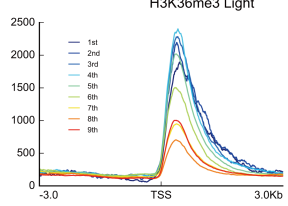

(b)

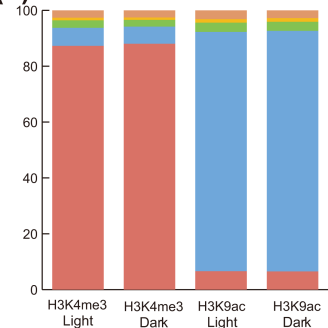

(e)

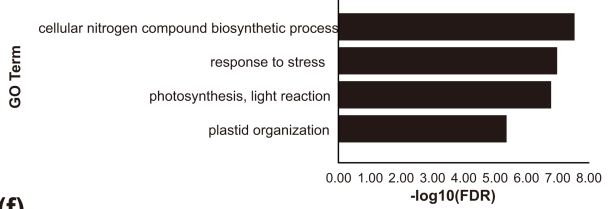

(f)

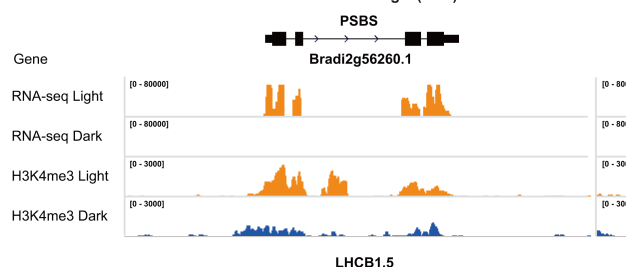

(h) Gene

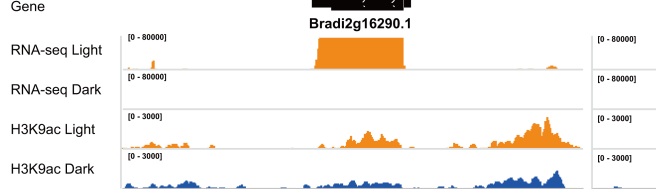

$=$ (d)

(c)
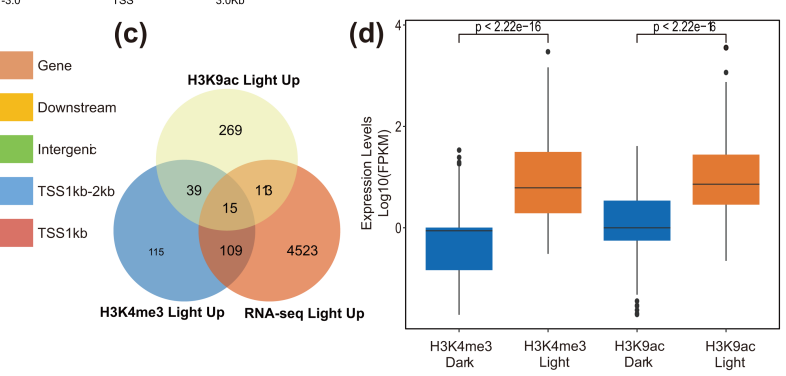

(g)

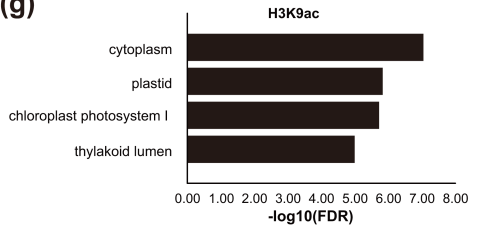

Bradi4g300602

NI)

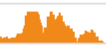

30000

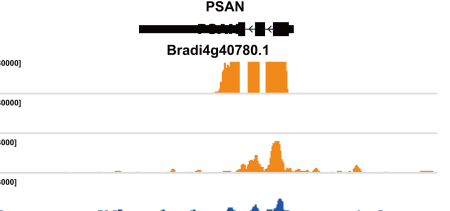




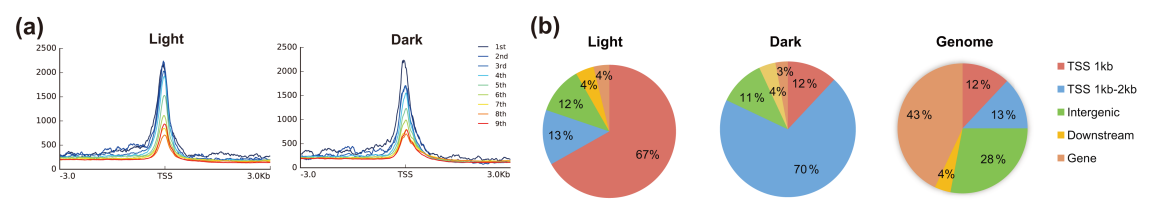

(c) RNA-seq Light

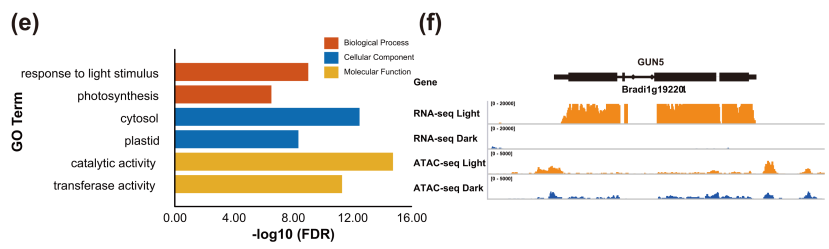

(d) RNA-seq Light

(g)

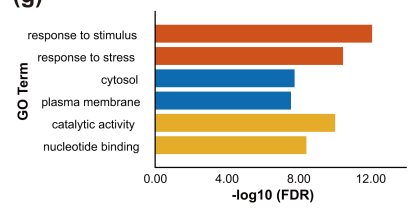

(h)

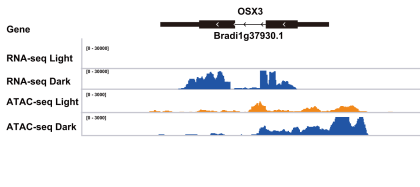

(a)

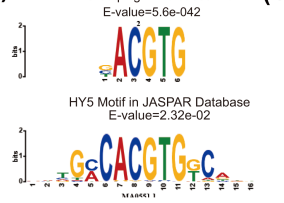

(c)

BdHY5-like Motif
E-value $=1.3 \mathrm{e}-047$

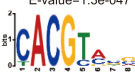

(d)

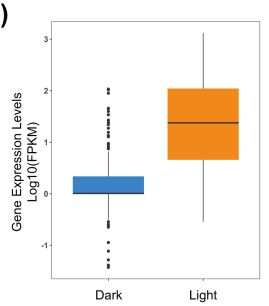

(b)

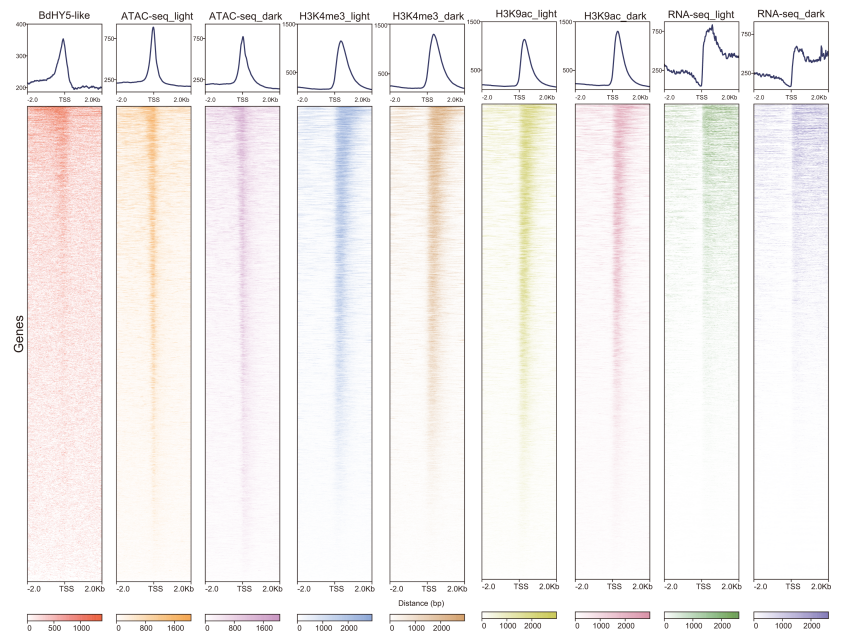

(a)

(b)

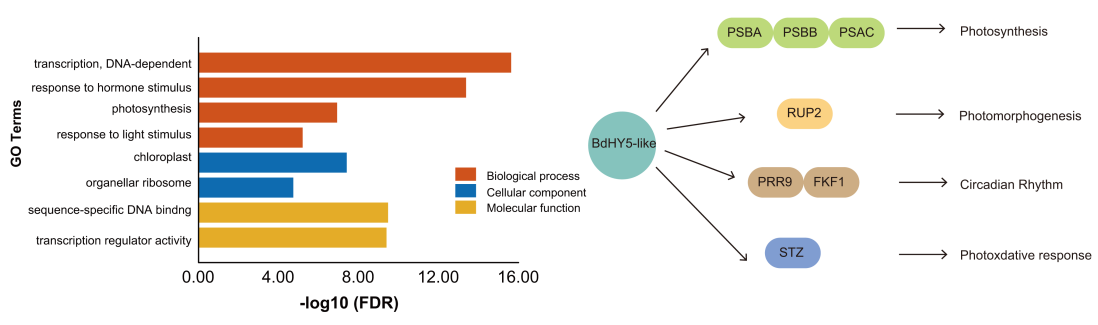

(c)

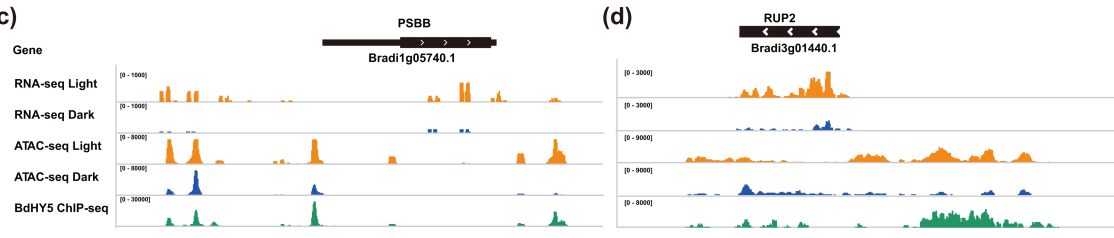


(a)

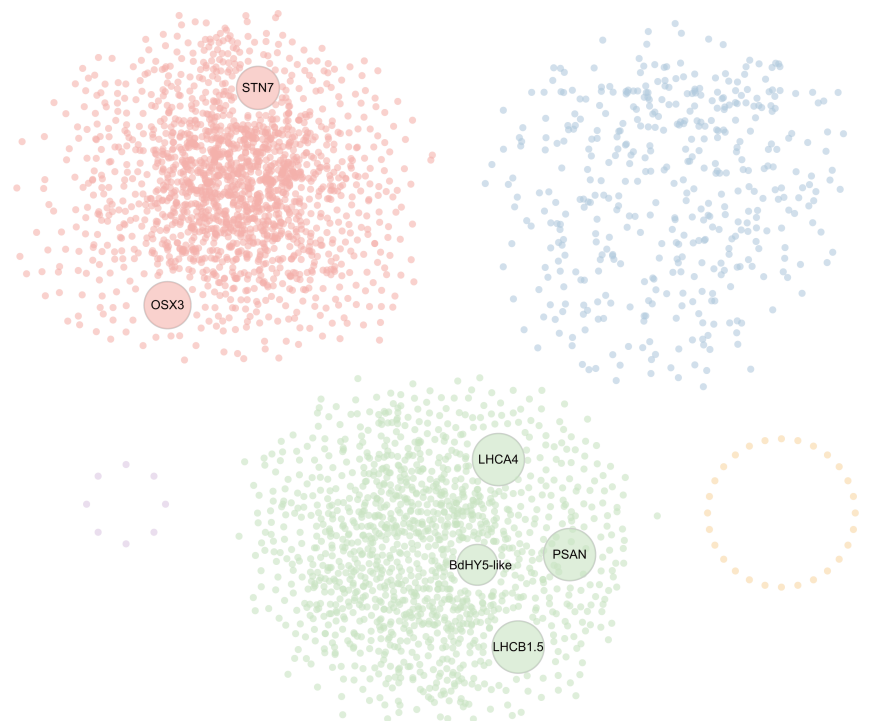

(b)

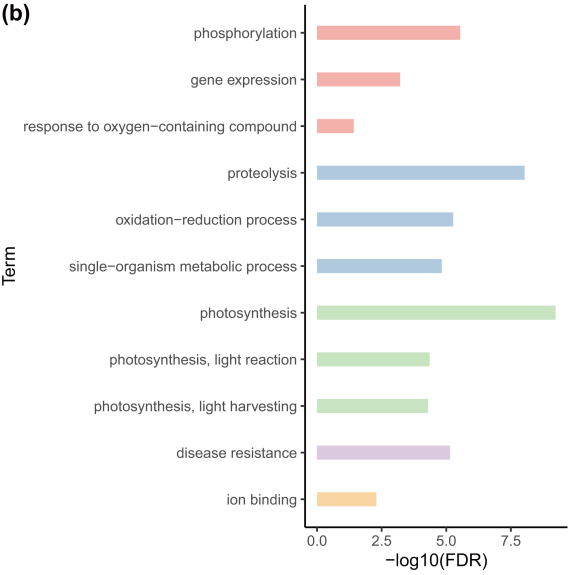

(c)

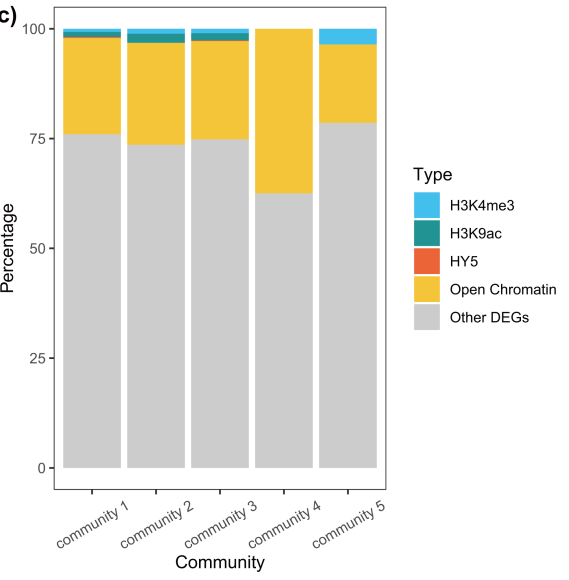

